\title{
sciendo LABORATORY TESTS OF A SPEED CONTROL SYSTEM FOR ROADHEADER CUTTING HEADS
}

doi:10.2478/mape-2018-0020

Date of submission of the article to the Editor: 03/2018

Date of acceptance of the article by the Editor: 06/2018

MAPE 2018, volume 1, issue 1, pp. 153-159

\author{
Dr. Jarosław Joostberens \\ Dr. Adam Heyduk \\ Silesian University of Technology, Poland
}

\begin{abstract}
:
The paper presents selected results of the laboratory tests of the speed control system for the R-130 roadheader with an inverter-fed cutting heads drive. The results recorded for the variable speed system have been compared with the measurement obtained for the network supplied drive. There have been noticed some oscillations after rapid current overloads. They are due to the operation of the internal current controller of the PWM-inverter, The oscillations are fast decaying - so they prove the results of initial system stability checking. Generally, the automatic speed control, tracking the optimum speed level calculating by supervisory speed adjuster makes possible to better utilize the motor power throughout the whole cutting time. The better operating conditions of the motor cause increase in the whole system power efficiency (even in spite of additional losses in the inverter circuit) Additionally the sped control reduces dynamical overloads. This fact can have a positive influence on the whole system reliability. The speed control subsystem is a part of the whole control system which contains also close-loop boom angular position and velocity control circuits.
\end{abstract}

Keywords: speed control, roadheader, cutting optimization, PI controller, power efficiency

\section{INTRODUCTION}

In Polish mining industry most of the roadways are now driven by a selective mechanical cutting using boom roadheaders. They are nowadays widely applied not only in mining engineering abut also in civil engineering (tunneling). When the coal seams are opened on deeper there is an increase of driving problems due to increase in rock compactness and their strength to uniaxial compression (Balci et al., 2004). Therefore one of the most important issues is to optimize their performance by the full use of their power in different operating conditions. In the currently produced roadheaders cutting head driving motors are supplied directly from a fixed frequency power supply network. Therefore the rock cutting process performed with an approximately constant angular speed of the head. In some situations the cutting process is carried out in conditions far from optimum. The angular speed of cutting head should be adjusted to the rock hardness. Generally, the harder the rock is, the lower should be the speed (Cheluszka et al., 2018). Such a principle can lower power consumption and knife wear intensity. It can be therefore useful to change the angular speed of the cutting heads by supply from the variable frequency inverter. Optimum cutting heads speed for particular operating conditions (rock type and hardness) can be calculated on a basis of several load torque parameters like mean value, variance, overload magnitude, duration and frequency etc. The exact method of this calculation is beyond scope of this paper. This optimum speed for a given operating conditions is periodically updated over a relatively long sampling interval (one full rotation period of a cutting head - that is more than $0.5 \mathrm{~s}$ ), but this reference speed signal has to be accurately tracked by a much faster internal closed-loop speed control system. 


\section{STRUCTURE AND DEVELOPMENT OF THE CONTROL SYSTEM}

The control system has been designed for the R-130 roadheader (Famur S.A.) equipped with a PWM-based frequency inverter. This type of roadheader with a mass of about 30 tons and the cutting head induction motor power $132 \mathrm{~kW}$ is a basic type of roadheader used in Polish coal industry (Cheluszka et al., 2018). The control system has been implemented using a National Instruments cRIO chassis with appropriate input and output cards. The simplified block diagram of the control system has been presented in Fig.1.

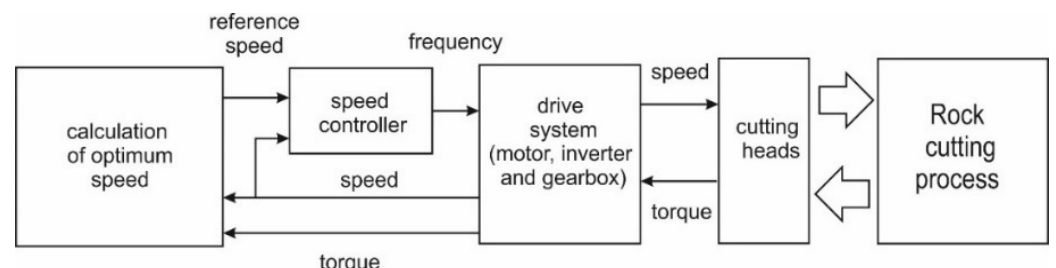

Fig. 1. Block diagram of the roadheader cutting heads speed control systems

Before laboratory tests, operation of the control system hardware and software has been tested using a software-implemented dynamical model of the roadheader and the Hardware in the Loop methodology. Optimum settings of the PI controller has been calculated using the model in the loop simulation and ITAE (Integral of Time multiplied by an Absolute value of Error) criterion (Tunia and Kazmierkowski, 1994). Stability of the system has been checked using a Nyquist criterion (O'Brien, 2012). Results of further laboratory tests have proven the correctness of theoretical analysis and numerical simulation and optimization (taking into account necessary model simplifications).the speed control system operates simultaneously with separate angular boom displacement control systems. Their joint action optimizes the depth cut, which is one of the most important parameters influencing the power consumption an overload intensity.

\section{PERFORMANCE OF THE AUTOMATIC CONTROL SYSTEM FOR CUTTING HEADS ANGULAR SPEED.}

\subsection{Reduction of dynamical overloads.}

One of important advantages of variable-speed driving system for the roadheader cutting heads is a reduction of their dynamical overloads - both mechanical and electrical. This is particularly noticeable at start-up as it has been shown in Figs. And As can be seen from comparison of Figs 2 and 3 the direct line start-up (Fig. 3) is much faster, but causes momentary current and torque overloads. The ramp-limited variable frequency start-up (Fig. 2 ) is longer but also much smoother. It can have a positive influence on the overall system reliability.

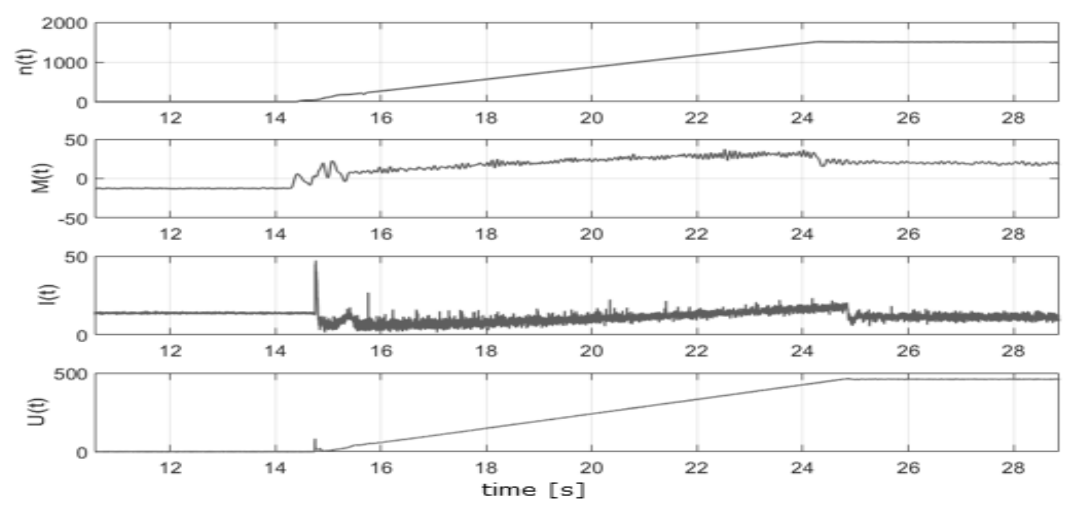

Fig. 2. Transients of rotational speed, electromagnetic torque, current and voltage at soft motor start-up with rate-limited variable frequency 


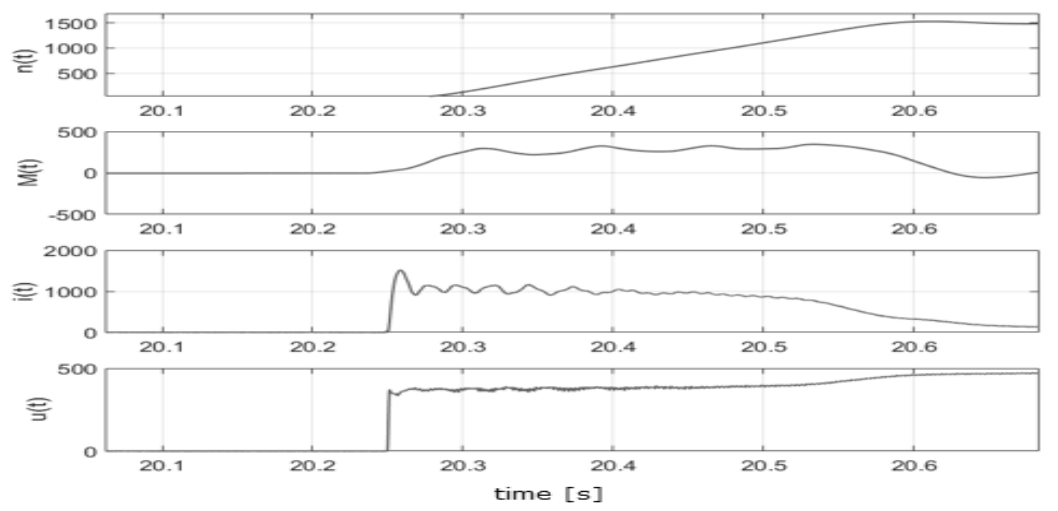

Fig. 3. Transients of rotational speed, electromagnetic torque, current and voltage at direct motor starting from the power supply network

\subsection{Speed oscillations and current overload}

Rock cutting load torque is a stochastic process (Mężyk et al., 2016; 2017) During the tests, there have been noticed the velocity oscillations. They have been probably caused by the operation of the current regulator which is an integral part of the frequency converter's control system. Momentary current overload of the motor causes its speed limitation (made to provide overload protection for inverter transistors) followed by oscillatory return to the reference value (Fig.4). This is due to the fact, that IGBT transistors are very sensitive to current overloads (Lorenz et al. 2001, Lorenz 2004). Therefore it is necessary to apply special current control and reduction methods (O'Sullivan, 2016; Trzynadlowski, 2016; Chokhawala and Castino, 1995; Chokhawala at al.,1995). The oscillations are fast decaying, so the closed-loop control system is stable with respect to disturbances. It proves the results of preliminary system stability check.
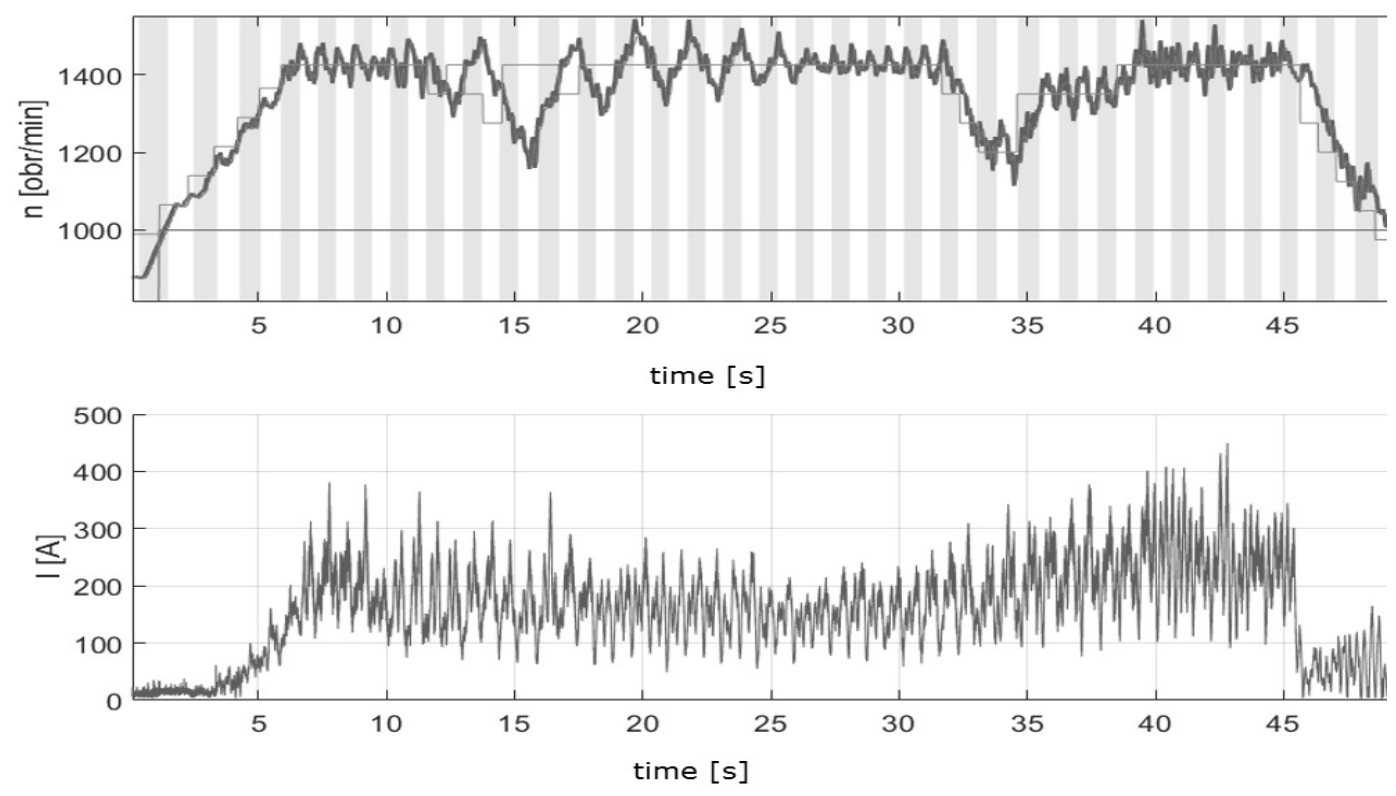

Fig. 4. An example of rotational speed reduction imposed by a current controller due to momentary current overload 


\section{POWER EFFICIENCY ASSESSMENT OF THE SPEED-CONTROLLED CUTTING HEADS DRIVE SYSTEM}

\subsection{Research methodology}

The analysis of recorded data regarding power and current consumption by the cutting heads drive has been carried out in order to verify the hypothesis about more favorable operating conditions of the drive with speed control. Due to the variability of mining conditions occurring within one cutting interval there has been assumed the (time-varying) time of one rotation of the cutting head as the basic unit for analysis. This rotation period value time has been determined based on the analysis of the synchronization signal. An example of this signal is shown in Fig. 5. (for the most readable run-out case) and in Fig. 6. (when powered from a frequency converter)

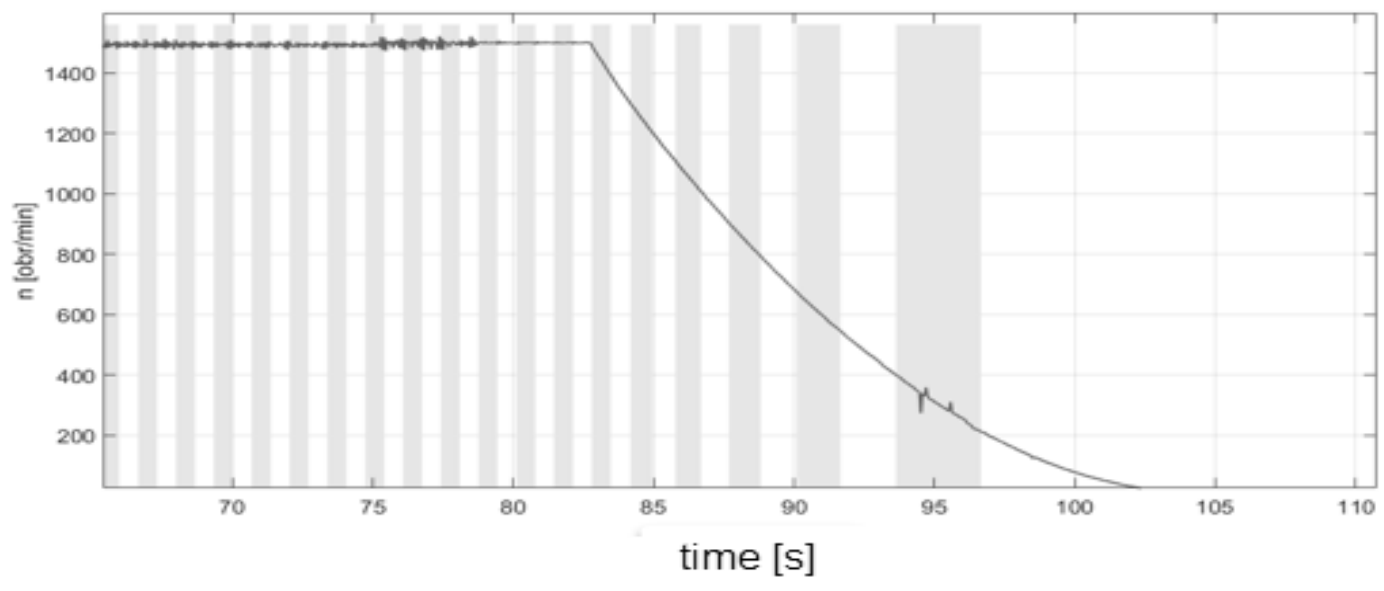

Fig. 5. Influence of motor rotational speed on the value of one cutting head rotation period at the power network supply

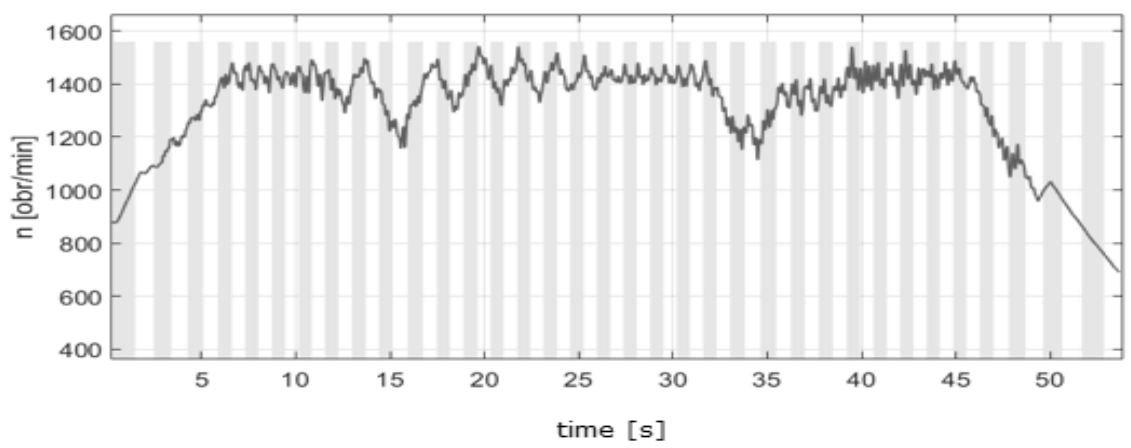

Fig. 6. Influence of motor rotational speed on the value of one cutting head rotation period at the frequency converter supply

After dividing the entire cutting interval into subintervals corresponding to the particular head rotation periods, several characteristic values (power, current, torque, speed) have been assessed for each rotation period. Since these values were subject to changes during one rotation, the variance and standard deviation were also determined in addition to the average value, and the median and dominant values per one rotation period.

\subsection{Results of laboratory tests}

In the analysis of a given cut, the start-up, switch-off and no-load periods have been neglected, i.e. only the periods for which the cutting head was in contact with the rock and the motor was loaded above $50 \%$ of its rated power have been taken into account. Incomplete cuts, e.g. 
vertical, inclusion, etc. were also omitted. The analysis has been carried out for selected (according to the above criteria) cuts for three types of power supply and control operation:

- with power network supply $(50 \mathrm{~Hz})$ as the most typical case of roadheader operation, treated as a reference point (Figs 7 and 9),

- with adjustable (though constant for the whole cutting time) speed and manual control

- when operating a roadheader with automatic control according to the developed algorithm.

(Figs. 8 and 10)

In the second case only the operation of the motor powered from the dual inverter module was taken into account, because operation with a single module supply did not allow using the full power of the motor to a level comparable even with work at the mains supply (due to frequent overcurrent protection operation and current regulator), hence the obtained results cannot be treated as reliable.

To assess the uniformity of the drive load during one revolution of the head, an overload factor was defined for each revolution, defined as the ratio of time in which the load exceeded $150 \%$ of the rated power to the entire duration of rotation. This coefficient takes values from the range $<0 ; 1>-$ the lower its value, the fewer temporary overloads occur during 1 rotation of the cutting head

Analysis of the results obtained is presented in the next section.

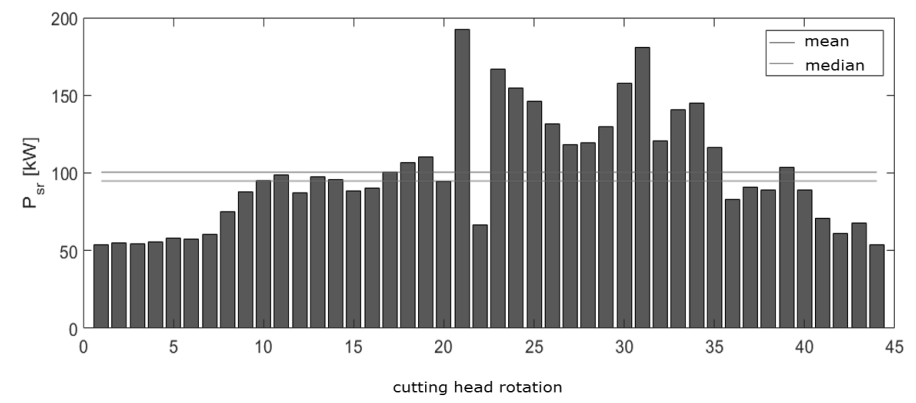

Fig. 7. Average motor load per 1 rotation period at $50 \mathrm{~Hz}$ power network supply

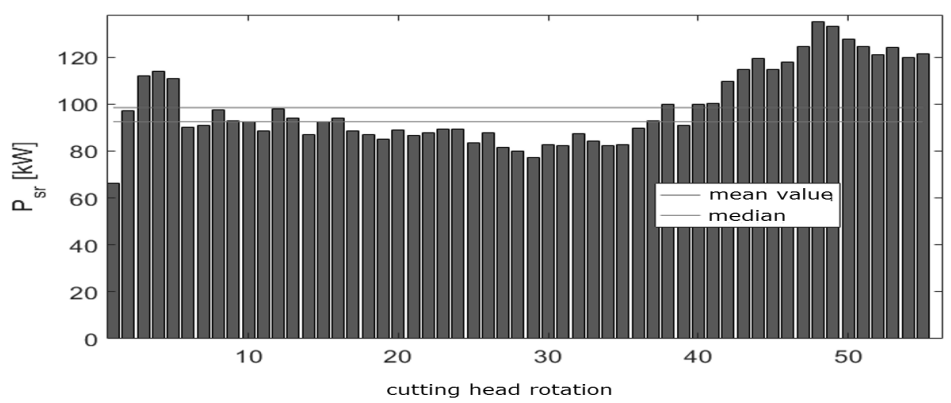

Fig. 8. Average motor load per 1 rotation period at automatic speed control

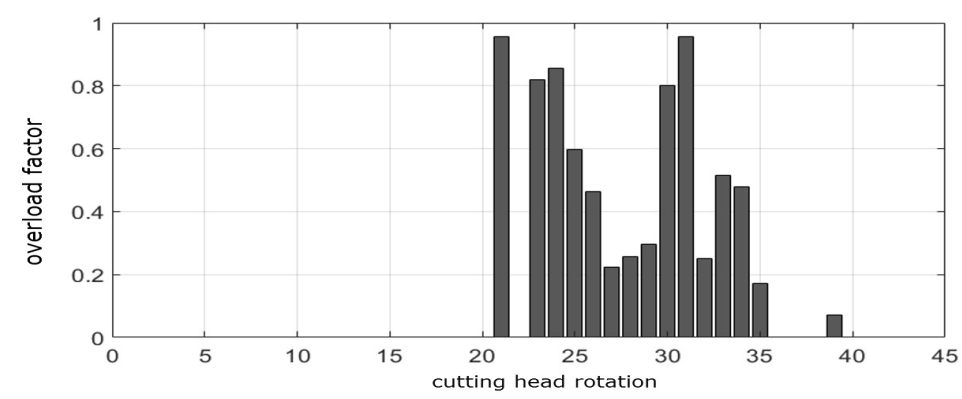

Fig. 9. Momentary motor overloads per 1 rotation period at $50 \mathrm{~Hz}$ power network supply 


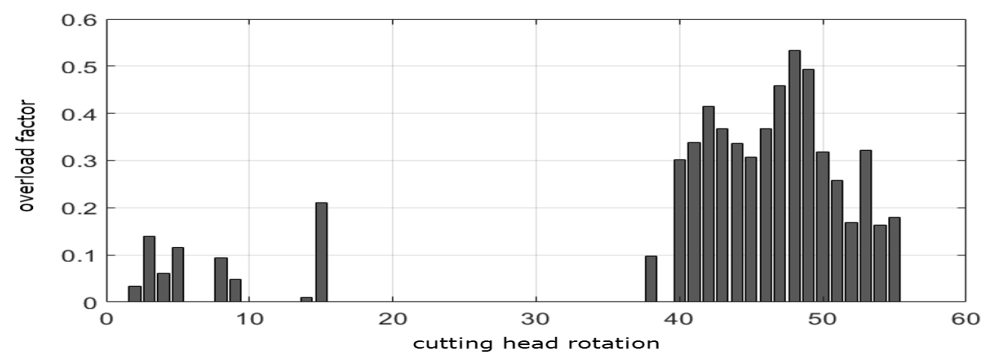

Fig. 10. Momentary motor overloads per 1 rotation period at automatic speed control (variable frequency)

\subsection{Overall system efficiency assessment}

Power averaging for one rotation period of the cutting head makes it easy to compare the mechanical power and electric power consumed from the network. As a result, it is also possible to determine the efficiency of the converter drive system (as a ratio of mechanical power to electric power) over the entire cutting cycle.

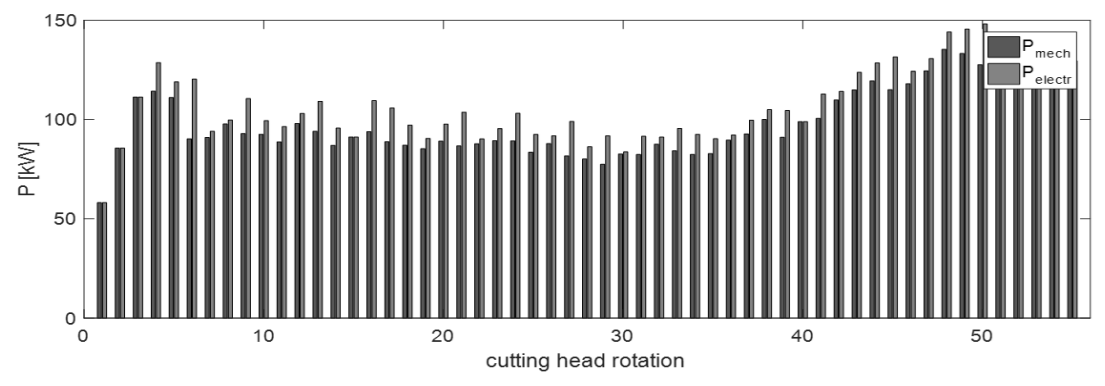

Fig. 11. Mechanical and electrical power for converter fed drive system per 1 rotation cycle for an example cut

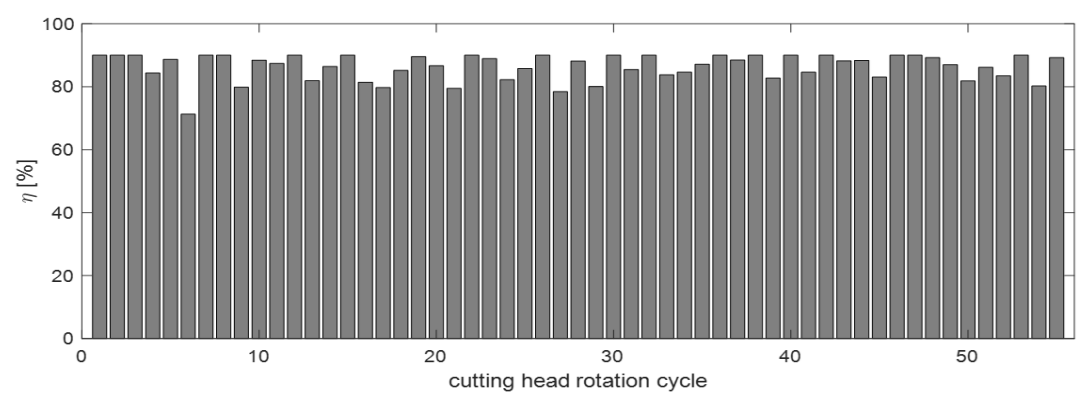

Fig. 12. Average efficiency value for converter-fed drive system per 1 rotation cycle for an example cut

Average efficiency value of the entire converter drive system in the case shown in Fig. 12. is about $85-87 \%$. Similar results were also obtained for other cuts with automatic speed control. When comparing the results, it can be clearly seen that the automatic adjustment of the rotational speed of the cutting head together with the automatic adjustment of the head inclination allows for a much better utilization of the power of the drive motor. In the case of direct power supply from the network, the use of motor power reached about $50 \%$ (Fig. 7) and when increasing to about $80 \%$, very frequent and large overloads appeared (Fig. 9). In the case of reduced frequency supply, similar phenomena occurred - either the use of $80 \%$ with frequent overloads or the motor underload $(60 \%)$ without. It was only the automatic speed control that enabled the motor to load about $80 \%$ of the nominal value (Fig. 9) with simultaneous reduction of overloads (Fig. 10). Even with a high load, longer periods are 
present without instantaneous overloads, which proves the effective selection of the operating point of the entire system.

\section{CONCLUSION}

Tests, carried out on the laboratory stand have proved, that a proposed speed control system fulfills design requirements, but can be also further optimized using more robust control structures and speed sensors with better dynamical parameters. One of the most important factors, having a great influence on dynamical performance of the whole system is a frequency rate limiter $(5 \mathrm{~Hz} / \mathrm{s})$ on the input of the power electronic inverter. This frequency rate limiter is necessary in order to prevent current overloads (Trzynadlowski, 2001) The variable speed (carefully adjusted to current operating conditions) makes possible to better utilize the motor power and in the same time reduce the frequency of mechanical and electrical overloads during the cutting process. Because of the better utilization of the motor nominal power, the whole system operates with high efficiency even considering additional losses in the inverter circuit. Reduction of dynamical overloads can improve the roadheader reliability. For the best performance the speed control system should operate simultaneously with other closed-loop control systems for horizontal and vertical angular displacement as they all have influence on the depth of cut, which is a very important parameter for load torque variation.

\section{ACKNOWLEDGEMENTS}

This work has been implemented under the research project entitled "Control of roadheader cutting heads movement for reduction of energy consumption of mining and dynamic loads" co-financed by the National Center for Research and Development under the Applied Research Projects (agreement no. PBS3/B2/15/2015)

\section{REFERENCES}

Balci, H., Demircin, M.A. and Copur, H. (2004). Estimation of Optimum Specific Energy Based on Rock Properties for Assessment of Roadheader Performance. J South Afr Inst Min Metall. vol. 104, No. 11., pp 633-641.

Cheluszka, P., Kaula, R., Heyduk, A. and Gawlik, J.(2018). Modelling the Dynamics of a Drive of BoomType Roadheader Cutting Heads at Adjustable Angular Speed. Arch. Min. Sci, vol. 63, No.1., pp 183-204.

Chokhawala, R. and Castino, G (1995). IGBT Fault Current Limiting Circuit. IEEE Ind. Appl. Mag., Vol. 1, no. 5., pp. 30-35.

Chokhawala, R.S, Catt, J. and Kiraly, L. (1995). A Discussion on IGBT Short-circuit Behavior and Fault Protection Schemes. IEEE Trans Ind. Appl., vol. 31, No. 2., pp. 256-263.

Lorenz, L. (2004). Overload capability and dynamic behaviour of low and high voltage IGBT and ultra fast softswitching diode. The 4th International Power Electronics and Motion Control Conference, IPEMC 2004., pp 320-326.

Lorenz, L. Mauder A. and Bauer J. (2001). Rated overload characteristics of IGBTs for low voltage and high voltage devices. 36 IAS Ind. Appl. Conference., pp 995-999.

Mężyk, A., Klein, W., Fice, M., Pawlak, M. and Basiura, K. (2016). Mechatronic model of continuous miner cutting drum driveline. Mechatronics, vol. 37, August, pp. 12-20.

Mężyk, A., Klein, W., Pawlak, M. and Kania, J. (2017). The identification of the vibration control system parameters designed for continuous miner machines. Int. J. Nonlinear Mech, vol. 91, May, pp. 181-188.

O'Brien, J. (2012). Frequency-Domain Control Design for High-Performance Systems. The Institution of Engineering and Technology, pp 54-63.

O'Sullivan, D.(2016). IGBT Overcurrent And Short-Circuit Protection In Industrial Motor Drives. Analog Devices, Inc., pp-1-6.

Trzynadlowski, A.M. (2001). Control of Induction Motors. Academic Press., pp 100-101.

Trzynadlowski, A.M. (2016). Introduction to modern Power Electronics (3 $3^{\text {rd }}$ ed). John Wiley \&Sons. pp 96-98.

Tunia, H. and Kaźmierkowski, M (1994). Automatic Control of Converter-Fed Drives. Elsevier. 